Article

\title{
Effect of Methyl $\beta$-cyclodextrin on Radical Scavenging Kinetics of Olive Leaf Extracts and Interactions with Ascorbic Acid
}

\author{
Vassilis Athanasiadis ${ }^{1,2}$ (D), Stavros Lalas ${ }^{2}$ and Dimitris P. Makris ${ }^{1, *}$ \\ 1 School of Environment, University of the Aegean, 81400 Lesbos, Greece; vs.athanas@gmail.com \\ 2 Department of Food Technology, Technological Educational Institute (T.E.I.) of Thessaly, 43100 Karditsa, \\ Greece; slalas@teilar.gr \\ * Correspondence: dmakris@aegean.gr; Tel.: +30-22540-83114
}

Received: 25 August 2017; Accepted: 7 September 2017; Published: 11 September 2017

\begin{abstract}
Olive leaf (OLL) extracts contain a high load of antioxidant polyphenols with significant pharmacological potency. In this study, the use of a novel natural deep eutectic solvent enabled the effective extraction of OLL polyphenols and their testing as radical scavengers, in the presence or absence of methyl $\beta$-cyclodextrin (m- $\beta$-CD), using descriptive kinetics. Testing was extended to include interactions with ascorbic acid-a natural powerful antioxidant-by implementing a response surface methodology. The kinetic study showed that $\mathrm{m}-\beta-\mathrm{CD}$ may hinder the radical scavenging effect of OLL extracts, yielding lower stoichiometry upon reaction with the radical probe 2,2-diphenyl-1-picrylhydrazy (DPPH). The extension of the reaction time to determine the total stoichiometry confirmed this effect. As a further concurrence, the interactions of OLL extracts with ascorbic acid showed lower radical scavenging performance in the presence of $\mathrm{m}-\beta-\mathrm{CD}$. These results were discussed on the grounds of the role that $\mathrm{m}-\beta-\mathrm{CD}$ may play in similar systems.
\end{abstract}

Keywords: antioxidants; deep eutectic solvents; methyl $\beta$-cyclodextrin; olive leaf extracts; polyphenols

\section{Introduction}

In recent years, there has been a growing demand for natural antioxidants to both replace synthetic ones and also to act as functional additives that could provide biological systems with protection against harmful free radicals. Plant-derived antioxidant polyphenols are becoming increasingly important in this respect, as numerous of these substances have been shown to possess a very high capacity for quenching free radicals [1]. This has stimulated a broad spectrum of studies regarding the use of plant extracts as rich sources of natural antioxidants. Olive leaves (OLL), which represent a major proportion of the waste generated during the production of olive oil, have attracted a great deal of interest because they may bear an important load of polyphenolic phytochemicals, which may possess beneficial biological properties [2].

Although antioxidant activity may be effectively estimated in plant extracts—with several tests developed for such a purpose [3] - a few studies have investigated in detail the rate of antiradical reactions, which might represent the rate at which antioxidants react with free radicals. Reaction kinetics information complements that of antiradical activity and may be of value for characterizing a potential antioxidant source. 2,2-diphenyl-1-picrylhydrazyl radical (DPPH) is widely used for quickly assessing the ability of antioxidants to transfer labile $\mathrm{H}$ atoms to radicals, based on the theory that a hydrogen donor is an antioxidant. This reaction is stoichiometric with respect to the number of hydrogen atoms absorbed. Therefore, the antioxidant effect can be easily evaluated by following the decrease of UV absorption at $515 \mathrm{~nm}$ [4]. 
On the basis of this theoretical background, this examination was carried out to assess the antiradical behaviour of OLL extracts obtained using a novel methodology that involved extraction with a combination of a deep eutectic solvent (DES) with methyl $\beta$-cyclodextrin (m- $\beta$-CD) as an extraction booster [5]. OLL extracts were also generated without $\mathrm{m}-\beta-\mathrm{CD}$, in order to evaluate the effect of $m-\beta-C D$ on the antiradical potency of the extracts. The investigations included a kinetic assay and also interactions with ascorbic acid (AA), after implementing a response surface methodology.

\section{Materials and Methods}

\subsection{Chemicals}

Anhydrous sodium carbonate came from Carlo Erba Reactifs (Val de Reuil, France). Methyl $\beta$-cyclodextrin was obtained from Acros Organics (Geel, Belgium). Folin-Ciocalteu reagent was from Fluka (Steinheim, Germany). Glycerol (99\%), 2,2-diphenyl-1-picrylhydrazyl (DPPH), gallic acid and ascorbic acid were from Sigma-Aldrich (Steinheim, Germany). Glycine (99.5\%) was from NeoLab Migge Laborbedarf-Vertiebs (Heildelberg, Germany).

\subsection{Preparation of the Deep Eutectic Solvent (DES)}

The Deep Eutectic Solvent (DES) used was synthesised according to the optimised conditions described previously in [6]. Briefly, glycerol (HBD) was mixed with an appropriate amount of glycine (HBA) and water to give a molar ratio of HBD:HBA:water of 7:1:3, and the mixture was mildly heated under stirring until the formation of a transparent liquid. An aqueous solution of $80 \%(\mathrm{w} / \mathrm{v})$ of this DES was used for the extractions.

\subsection{Plant Material}

The material used for all extractions was dried Olea europaea leaf (OLL) powder, with an average particle diameter of $0.5 \mathrm{~mm}$. Details concerning the variety and methodology of leaf collection and the handling of the plant material have been analytically given elsewhere [6].

\subsection{Batch Extraction Procedure and Sample Handling}

Polyphenol-containing extracts were prepared from OLL by implementing the optimized methodology previously developed in [5]. Briefly, $2.5 \mathrm{~g}$ of dried OLL was mixed with $100 \mathrm{~mL}$ of $80 \%$ $(\mathrm{w} / \mathrm{v})$ aqueous DES containing $9 \%(\mathrm{w} / \mathrm{v})$ methyl $\beta$-cyclodextrin $(\mathrm{m}-\beta-\mathrm{CD})$ and extractions were carried out at $70{ }^{\circ} \mathrm{C}$, under continuous stirring at $600 \mathrm{rpm}$ for $280 \mathrm{~min}$. Extractions without $\mathrm{m}-\beta-\mathrm{CD}$ were also performed under identical conditions. Samples were centrifuged in a table centrifuge (Hermle, Wehingen, Germany) at 10,000 $\times g$ for $10 \mathrm{~min}$, and the clear extract was used for all assays.

\subsection{Total Polyphenol Determination}

Total polyphenols were determined with the Folin-Ciocalteu reagent, following a previously published protocol [7]. Results were expressed as mg gallic acid equivalents per $\mathrm{L}$ of extract, using a gallic acid calibration curve (30-600 $\left.\mathrm{mg} \mathrm{L}^{-1}\right)$.

\subsection{Kinetic Assay}

The ability of the extracts to transfer H-atoms to DPPH was assessed by measuring changes in the absorbance at $515 \mathrm{~nm}\left(A_{515}\right)$. Typically, $0.975 \mathrm{~mL}$ of freshly prepared DPPH solution in methanol $(100 \mu \mathrm{M})$, was mixed in a spectrometer cell with $0.025 \mathrm{~mL}$ of OLL extract. The decay in $A_{515}$ was monitored over a period of $2 \mathrm{~min}$ to determine rate constant $\left(k_{1}\right)$. The assay was extended up to $21 \mathrm{~min}$ for the determination of total stoichiometries $\left(n_{t}\right)$. 


\subsection{Interaction with Ascorbic Acid}

The methodology implemented was a $3 \times 3$ central composite design, aimed at investigating the interactions between OLL extracts and ascorbic acid and to clarify the effect of $\mathrm{m}-\beta-\mathrm{CD}$. Thus the two independent variables chosen were the total polyphenol concentration of the extracts $\left(C_{\mathrm{TP}}, \mathrm{mg}\right.$ GAE $\left.\mathrm{L}^{-1}\right)$, termed as $X_{1}$, and the ascorbic acid concentration $\left(C_{\mathrm{AA}}, \mathrm{mg} \mathrm{L}^{-1}\right)$, termed as $X_{2}$. A central composite experimental design was used with two central points and both independent variables were coded between -1 (lower limit) and +1 (upper limit), using the following equation:

$$
x_{i}=\frac{X_{i}-X_{0}}{\Delta X_{i}}, i=1,2
$$

Terms $x_{i}$ and $X_{i}$ represent the dimensionless and the actual value of the independent variable $i$, respectively. $X_{0}$ is the actual value of the independent variable $i$ at the central point of the design, and $\Delta X_{i}$ the step change of $X_{i}$, which corresponds to a unit change of the dimensionless value (Table 1). The choice for the range of values for both variables was based on preliminary runs, but also on published information [8]. The response considered was the antiradical activity $\left(A_{\mathrm{AR}}\right)$. ANOVA was performed to estimate model significance, the significance for each polynomial coefficient, and determine the overall coefficient $R^{2}$ for the mathematical model. Statistically non-significant dependent terms $(p>0.05)$ were removed from the equations, which were visualised in the form of 3D plots. The models were validated by performing experiments under the predicted optimal conditions, and comparing for each model the predicted values with the actual (measured) ones. For each design point, measured and predicted response values were recorded (Table 2). For each design point, $C_{\mathrm{TP}}$ and $C_{\mathrm{AA}}$ were fixed as dictated by the experimental design. $A_{\mathrm{AR}}$ ( $\mu$ mol DPPH $\mathrm{g}^{-1}$ dry OLL weight) was determined as described elsewhere [9].

Table 1. Actual values and coded levels of the independent variables used for the experimental design.

\begin{tabular}{ccccc}
\hline Independent Variables & Code Units & \multicolumn{3}{c}{ Coded Variable Level } \\
\hline & & -1 & 0 & 1 \\
$C_{\mathrm{TP}}\left(\mathrm{mg} \cdot \mathrm{L}^{-1}\right)$ & $X_{1}$ & 10 & 40 & 70 \\
$C_{\mathrm{AA}}\left(\mathrm{mg} \cdot \mathrm{L}^{-1}\right)$ & $X_{2}$ & 10 & 40 & 70 \\
\hline
\end{tabular}

Table 2. Measured and predicted $A_{\mathrm{AR}}$ values of OLL extract and AA mixtures, determined for individual design points.

\begin{tabular}{|c|c|c|c|c|c|c|}
\hline \multirow[t]{3}{*}{ Design Point } & \multicolumn{2}{|c|}{ Independent Variables } & \multicolumn{4}{|c|}{ Response $\left(A_{\mathrm{AR}}, \mu \mathrm{mol} \mathrm{DPPH} \mathrm{g}^{-1} \mathrm{dw}\right)$} \\
\hline & \multirow[b]{2}{*}{$X_{1}$} & \multirow[b]{2}{*}{$X_{2}$} & \multicolumn{2}{|c|}{ Without $\mathrm{m}-\beta-\mathrm{CD}$} & \multicolumn{2}{|c|}{$m-\beta-C D$} \\
\hline & & & Measured & Predicted & Measured & Predicted \\
\hline 1 & -1 & -1 & 91.04 & 90.58 & 82.13 & 82.06 \\
\hline 2 & -1 & 1 & 22.85 & 19.14 & 18.87 & 15.04 \\
\hline 3 & 1 & -1 & 166.02 & 168.98 & 140.08 & 143.39 \\
\hline 4 & 1 & 1 & 96.88 & 96.59 & 82.68 & 82.23 \\
\hline 5 & -1 & 0 & 35.5 & 39.68 & 31.81 & 35.71 \\
\hline 6 & 1 & 0 & 120.27 & 117.60 & 102.84 & 99.98 \\
\hline 7 & 0 & -1 & 141.99 & 139.50 & 124.61 & 121.37 \\
\hline 8 & 0 & 1 & 63.58 & 67.58 & 53.00 & 57.28 \\
\hline 9 & 0 & 0 & 89.11 & 88.36 & 78.18 & 76.49 \\
\hline 10 & 0 & 0 & 89.11 & 88.36 & 75.83 & 76.49 \\
\hline
\end{tabular}

\subsection{Statistics}

Curve-fittings of absorbance vs. time were carried out by non-linear regression. The kinetic model was obtained by performing linear regression. All analyses were carried out at least at a $95 \%$ significance level, using SigmaPlot ${ }^{\mathrm{TM}}$ 12. The experimental design for the response surface methodology and all associated statistics was accomplished with JMPTM 10. 


\section{Results and Discussion}

\subsection{Reaction Stoichiometries and the Effect of $m-\beta$-Cyclodextrin}

The H-transfer reactions from polyphenols to DPPH can be very effectively assessed by monitoring the decay of $A_{515}$, using as molar absorptivity $\varepsilon=11,240 \mathrm{M}^{-1} \mathrm{~cm}^{-1}$ and considering the purity of the reagent. The decay in $A_{515}$ is initiated following addition of the antioxidant(s) to the DPPH solution [10] and potent antioxidants may provoke a rapid decay over 1-2 $\mathrm{min}$, as a result of the transfer of $\mathrm{H}$-atoms of the antioxidant that possess low $\mathrm{C}$-H bond dissociation enthalpies (fast step). This step is followed by a much slower decline in $A_{515}$, which corresponds to the donation by the antioxidant(s) of the residual H-atoms (slow step) [11,12].

A simple hypothesis considers that an antioxidant $\mathrm{AH}$ bears $n$ independent antioxidant subunits, which may all transfer a single $\mathrm{H}$ atom to DPPH with the same second-order rate constant $k$ [4]. Such a background can be described as follows:

$$
\begin{gathered}
A=\varepsilon[\mathrm{DPPH}] \\
R=-\frac{d}{d t}[\mathrm{AH}]=-\frac{d}{d t}[\mathrm{DPPH}]=k[\mathrm{AH}][\mathrm{DPPH}]
\end{gathered}
$$

As mentioned above, the initial (fast) step of the reaction actually represents the donation of the most readily abstracted $\mathrm{H}$-atoms from the antioxidant. Hence the initial reaction rate $R_{0}$ could be given as:

$$
R_{0}=k_{1} c c_{0}
$$

where $c$ is the initial antioxidant concentration, $c_{0}$ is the initial DPPH concentration and $k_{1}$ the reaction rate constant of the first abstracted $\mathrm{H}$-atom. Therefore $k$ would be $\frac{k_{1}}{n}$. Based on Beer-Lambert's law, the [DPPH] that reacts with the first $\mathrm{H}$-atom may be represented as $A_{0}-A_{f}$, where $A_{0}$ and $A_{f}$ correspond to the initial and final $A_{515}$. Thus by replacing [DPPH] with $A_{0}-A_{f}$, the Equation (3) can be transformed after integration, as follows:

$$
\ln \left(\frac{1-\frac{A_{f}}{A}}{1-\frac{A_{f}}{A_{0}}}\right)=\frac{k_{1} c}{\frac{A_{0}}{A_{f}}-1}
$$

The slope of the straight line obtained after plotting $\ln \left(\frac{1-\frac{A_{f}}{A}}{1-\frac{A_{f}}{A_{0}}}\right)$ as a function of time $t$, equals $k_{1}$.

On such a theoretical basis, OLL extracts obtained with or without $\mathrm{m}-\beta-\mathrm{CD}$ were assayed with the aim to clarifying the role of $\mathrm{m}-\beta-\mathrm{CD}$ on the antiradical effects exerted by OLL polyphenols. To this purpose, the extracts generated were adjusted at a final $C_{\mathrm{TP}}$ of $0.1 \mathrm{~g} \mathrm{~L}^{-1}$ and reaction with DPPH was monitored up to 2 minutes (Figure 1, upper plot). Determination of $k_{1}$ was performed by tracing the second order kinetics (Figure 1, lower plot) and gave values of 1.925 and $2.221 \mathrm{M}^{-1} \mathrm{~s}^{-1}$, for the extract obtained with DES/m- $\beta$-CD and DES, respectively. The slower reaction rate of the extract obtained with DES/m- $\beta$-CD compared with that obtained only with DES could not be interpreted as weaker antiradical activity, but only as a measure of the radical scavenging rate. This is because several polyphenolic antioxidants were shown to respond differently in kinetic and stoichiometric assays based on reaction with DPPH [13]. 


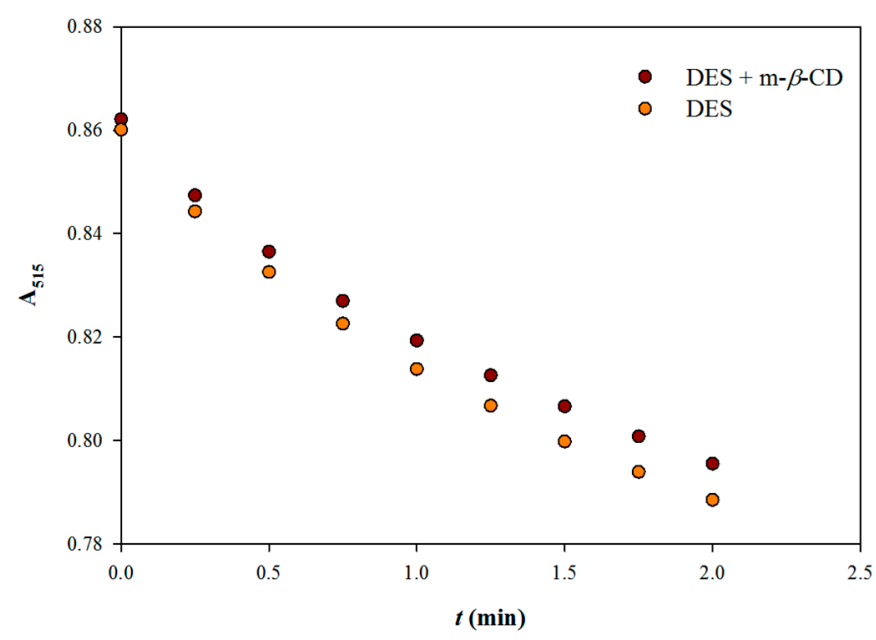

(a)

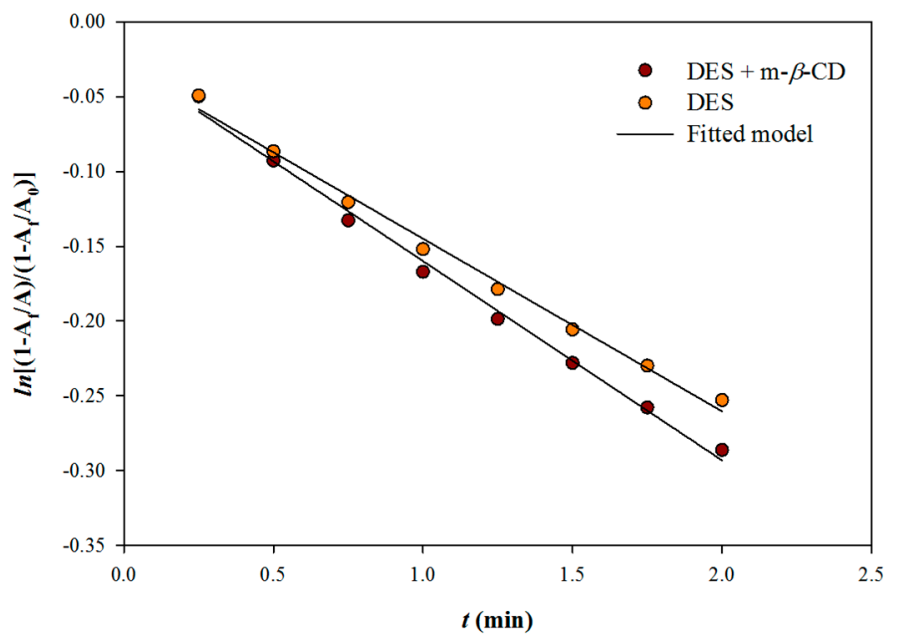

(b)

Figure 1. Fast reaction kinetics recorded upon mixing OLL extract with DPPH. $C_{\mathrm{TP}}$ was adjusted to $0.1 \mathrm{~g} \mathrm{~L}^{-1}, c_{0}$ was $100 \mu \mathrm{mol} \mathrm{L}{ }^{-1}$. (a) Time course of $\mathrm{A}_{515}$ decrease within the first two minutes; (b) Second-order kinetics.

Thus in order to have a more integrated picture, the total stoichiometries $\left(n_{t}\right)$ were also determined by extending the reaction of each extract with DPPH, up to 21 min (Figure 2), using the following equation:

$$
n_{t}=\frac{A_{0}-A_{f}}{\varepsilon C_{\mathrm{TP}}}
$$

where $C_{\mathrm{TP}}$ is the total polyphenol concentration of the extracts, which as mentioned above was adjusted to $0.1 \mathrm{~g} \mathrm{GAE} \mathrm{L}^{-1}$. Determination of $n_{\mathrm{t}}$ for the DES $/ \mathrm{m}-\beta-\mathrm{CD}$ and DES extracts gave corresponding values of $1.05 \times 10^{-4}$ and $1.92 \times 10^{-4} \mathrm{~mol} \mathrm{~g}^{-1}$, indicating higher stoichiometry for the extract in the absence of $\mathrm{m}-\beta$-CD. 


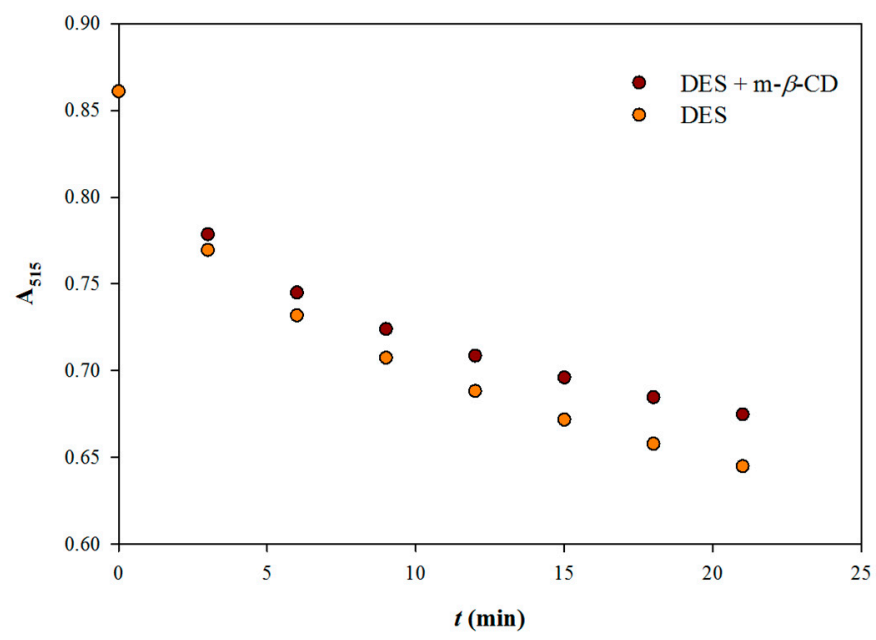

Figure 2. Extended reaction kinetics recorded upon mixing OLL extract with DPPH. $C_{\mathrm{TP}}$ was adjusted to $0.1 \mathrm{~g} \mathrm{~L}^{-1}, c_{0}$ was $100 \mu \mathrm{mol} \mathrm{L}{ }^{-1}$.

Considering both $k_{1}$ and $n_{\mathrm{t}}$, it could be argued that the extract obtained only with DES displayed superior radical scavenging potency. This finding contrasted previous ones, which demonstrated that polyphenol-containing extracts obtained with the aid of various cyclodextrins, such as Melissa officinalis leaf extract [14] and pomegranate fruit extract [15] exhibited increased antiradical activity. Likewise, simple phenolics such as rosmarinic acid [16], chlorogenic acid [17] and trans-resveratrol [18], and quercetin and glycosides therof [19], showed improved antioxidant properties when they were encapsulated in cyclodextrins. However, a detailed study on the inclusion complexes of tea catechins suggested that the nature of the polyphenol, as well as the orientation of the encapsulated molecule inside the cyclodextrin cavity, may affect antioxidant potency either negatively or positively [20].

Hydrophobicity would be an issue in this regard, because cyclodextrin/polyphenol inclusion complexes may be better stabilized with molecules having higher hydrophobicity [21]. On the other hand, hydrogen bonding could also greatly affect the antioxidant behaviour of the complexed polyphenols, because if there is extended intermolecular hydrogen bond development between the encapsulated and the host molecule, then radical scavenging is abrogated [22]. Such a claim was made for the apparent null effect of hydroxypropyl $\beta$-CD on caffeic acid antioxidant potency [23], where intramolecular hydrogen bond between the hydroxyl groups of the $o$-diphenol moiety would not allow for intermolecular interactions. On the basis of the above concepts, it could be supported that there might be a slower reaction for the OLL extract with DPPH in the presence of $m-\beta-C D$. This phenomenon might be ascribed to the inclusion of OLL polyphenols inside the $\mathrm{m}-\beta$-CD cavity, which could slow down H-atom transfer to DPPH due to steric effects. Such a hypothesis would be concurred by the fact that complexation of oleuropein, the most abundant polyphenolic antioxidant in OLL, most probably involves deep insertion of the dihydroxyphenethyl moiety inside the cavity from its secondary side, as demonstrated for OLL interactions with $\beta$-cyclodextrin $(\beta$-CD) [21]. The formation of similar inclusion complexes with of $\beta$-CD has also been shown for chlorogenic acid [24].

\subsection{Interactions with Ascorbic Acid}

In an earlier study, interactions of polyphenol-containing extract with ascorbic acid (AA) were very effectively examined using response surface methodology [8]. It was proposed that by combining fixed amounts of AA and total polyphenols is a rather unilateral approach, providing limited information, whereas the simultaneous variation of concentrations within predetermined ranges may be more illustrative of the kind of interactions. This is because it has been demonstrated that the relevant amounts of AA and polyphenols in a mixture may significantly affect the overall antioxidant effect [25]. 
On these grounds, a response surface design was deployed to evaluate interactions between OLL extract and AA. Evaluation of term contribution by performing ANOVA showed that $C_{\mathrm{TP}}$ and $C_{\mathrm{AA}}$ and their quadratic terms exerted statistically significant effects on the $A_{\mathrm{AR}}$ of the mixtures. However, cross terms were non-significant in this regard $(p>0.05)$ and thus they were omitted from the models (mathematical equations), which are presented in their final form in Table 3 . The use of the desirability function (Figure 3 ) enabled the determination of the settings recommended to achieve $A_{\mathrm{AR}}$ maximisation. Under these $C_{\mathrm{TP}}$ and $C_{\mathrm{AA}}$ combinations, maximum $A_{\mathrm{AR}}$ was estimated to be 168.98 \pm 10.43 and $143.39 \pm 11.18 \mu \mathrm{mol}$ DPPH g ${ }^{-1} \mathrm{dw}$, for the extracts obtained with DES/m- $\beta$-CD and DES, respectively. As can be seen in Figure 4, the interaction pattern with AA was identical, but the difference of $15 \%$ in performance was a further confirmation that the OLL extract could act as a better radical scavenger in the absence of $\mathrm{m}-\beta-\mathrm{CD}$.

Table 3. Polynomial equations and statistical parameters describing the effect of the independent variables on the response $\left(A_{\mathrm{AR}}\right)$ for all OLL/AA mixtures tested.

\begin{tabular}{cccc}
\hline Antioxidant Test & $\mathbf{2}^{\text {nd }}$ Order Polynomial Equations & $\boldsymbol{R}^{\mathbf{2}}$ & $\boldsymbol{p}$ \\
\hline Without $\mathrm{m}-\beta-\mathrm{CD}$ & $88.36+38.96 C_{T P}-35.96 C_{A A}-9.72 C_{T P}^{2}+15.18 C_{A A}^{2}$ & 1.00 & $<0.0001$ \\
With $\mathrm{m}-\beta-\mathrm{CD}$ & $76.49+32.13 C_{T P}-32.04 C_{A A}-8.64 C_{T P}^{2}+12.84 C_{A A}^{2}$ & 0.99 & 0.0002 \\
\hline
\end{tabular}

\section{Without $\mathrm{m}-\beta-\mathrm{CD}$}

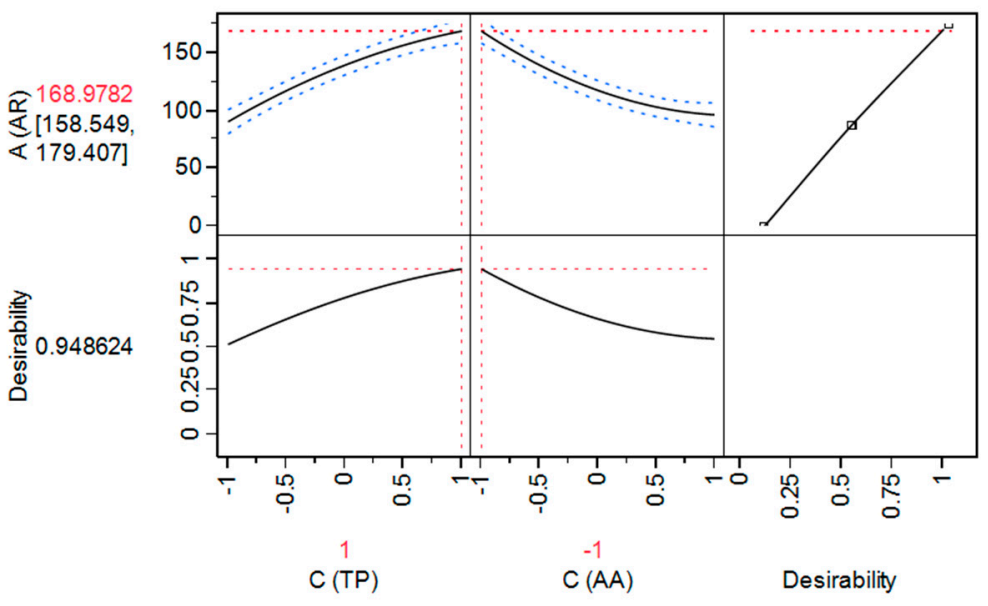

\section{With $\mathrm{m}-\beta-\mathrm{CD}$}

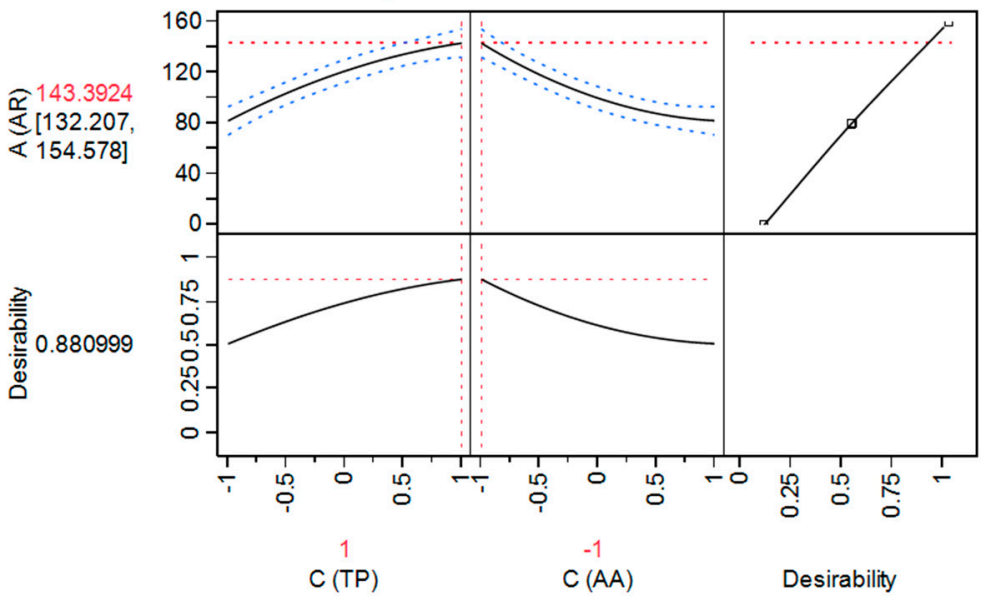

Figure 3. Prediction profiler displaying the overall desirability of the model developed, after implementing response surface methodology. 
Without $\mathrm{m}-\boldsymbol{\beta}-\mathrm{CD}$

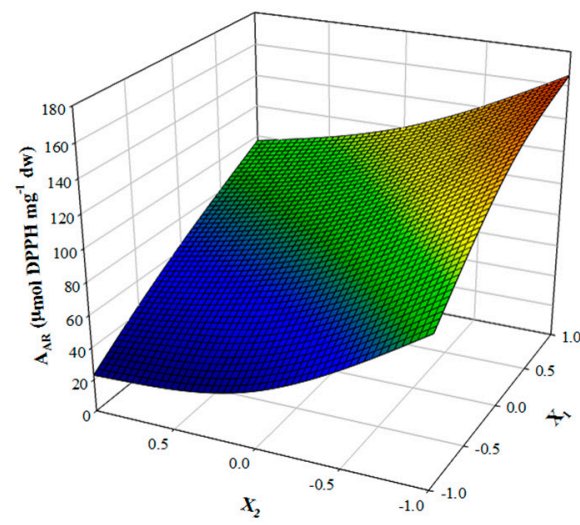

(a)
With $\mathrm{m}-\boldsymbol{\beta}-\mathbf{C D}$

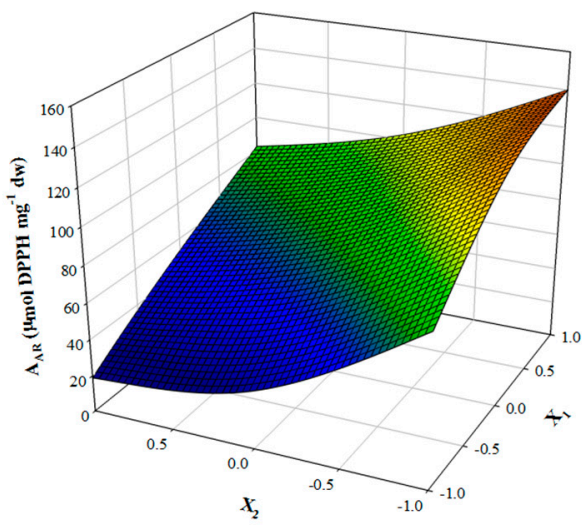

(b)

Figure 4. 3D plots illustrating the effect of simultaneous variation of $C_{\mathrm{TP}}$ and $C_{\mathrm{AA}}$ on the $A_{\mathrm{AR}}$ in the (a) absence and (b) presence of $\mathrm{m}-\beta-\mathrm{CD}$.

The optimal estimated ratio of $C_{\mathrm{TP}} / C_{\mathrm{AA}}$ to attain maximum $A_{\mathrm{AR}}$ was in both cases $7 / 1$ (Table 4 ), which clearly indicated that the switching of $C_{\mathrm{AA}}$ to higher levels would not provide higher $A_{\mathrm{AR}}$. This particular antiradical behaviour of the OLL extract/AA would most probably be ascribed to the nature of the major radical scavengers occurring in OLL extracts. In previous studies pertaining to $A_{\mathrm{AR}}$ of mixtures of polyphenol-containing extracts with AA, it was shown that grape stem extracts displayed the highest performance when combined with $\mathrm{AA}$ at a $C_{\mathrm{TP}} / C_{\mathrm{AA}}$ ratio of $1 / 1$ [8], but for grape seed extracts optimal ratio of $0.82 / 1$ was also determined [26]. These findings suggested that the nature of principal antioxidant polyphenols in an extract might greatly define the antiradical effects. Investigations with pure polyphenols including quercetin, hesperetin and ferulic acid, revealed that interactions with AA at molar ratio 1:1 yielded antagonism [27], a behaviour that was confirmed by a following detailed study on reducing power, employing response surface methodology [28]. In this study, however, it was shown that the maximum response in hesperetin/AA mixtures was achieved at a molar ratio of 5.2/1, which clearly indicated that the nature of polyphenolic antioxidant may define the molar ratio that could yield maximum antioxidant effect, in combination with AA. Furthermore, other authors supported that compounds that are co-extracted with polyphenols from OLL could also interfere [29], but such an effect remains to be elucidated.

Table 4. Optimal, predicted concentration ratios and theoretically calculated maximum response for all mixtures tested, obtained from the implementation of design.

\begin{tabular}{ccc}
\hline Antioxidant Test & Maximum Predicted Response & Optimal Ratio \\
\hline Without $\mathrm{m}-\beta-\mathrm{CD}$ & $168.98 \pm 10.43$ & $70 / 10$ \\
With $\mathrm{m}-\boldsymbol{\beta}$-CD & $143.39 \pm 11.18$ & $70 / 10$ \\
\hline
\end{tabular}

\section{Conclusions}

The examination of the effect of $\mathrm{m}-\beta-\mathrm{CD}$ on the radical scavenging ability of OLL polyphenols was approached first by a kinetic assay to determine stoichiometry and second by a response surface methodology to investigate interactions with the natural antioxidant ascorbic acid. In spite of the references reporting on the enhancement of the antioxidant activity of polyphenols in the presence of various cyclodextrins, this study demonstrated that $m-\beta-C D$ may lower the radical efficiency of OLL polyphenols. A similar outcome was observed in the interactions between OLL polyphenols and ascorbic acid, which was a further concurrence of the hindering effect of $m-\beta-C D$. Based on the evidence found by this investigation, it was postulated that the orientation of oleuropein-the 
most abundant OLL antioxidant-inside the $\mathrm{m}-\beta-\mathrm{CD}$ cavity, as well as the interactions between the encapsulated polyphenols and $\mathrm{m}-\beta-\mathrm{CD}$ may be responsible for the phenomena observed. It is proposed that further studies with different $\beta$-cyclodextrin derivatives are required to fully clarify the mechanism of suppression (or enhancement) of the antiradical activity of polyphenol-containing extracts.

Acknowledgments: The authors acknowledge partial support from the Department of Technology (Technological Educational Institute of Thessaly).

Author Contributions: Vassilis Athanasiadis carried out the experimental work; Stavros Lalas and Dimitris P. Makris conceived the theoretical background, handled and analysed the results and wrote the paper.

Conflicts of Interest: The authors declare no conflict of interest.

\section{Nomenclature}

$\begin{array}{ll}A_{0} & \text { initial absorbance at } 515 \mathrm{~nm} \\ A_{t} & \text { absorbance at } 515 \mathrm{~nm} \text { at any time } t \\ A_{\mathrm{AR}} & \text { antiradical activity }\left(\mu \mathrm{mol} \mathrm{DPPH} \mathrm{g} \mathrm{m}^{-1} \mathrm{dry} \text { weight }\right) \\ c_{1} & \text { initial antioxidant concentration }\left(\mathrm{mol} \mathrm{L}^{-1}\right) \\ c_{0} & \text { initial DPPH concentration }\left(\mathrm{mol} \mathrm{L}^{-1}\right) \\ C_{\mathrm{AA}} & \text { ascorbic acid concentration }\left(\mathrm{mg} \mathrm{L}^{-1}\right) \\ C_{\mathrm{TP}} & \text { total polyphenol concentration }\left(\mathrm{mg} \mathrm{L}^{-1}\right) \\ \varepsilon & \text { molar absorptivity }\left(\mathrm{M}^{-1} \mathrm{~cm}^{-1}\right) \\ k & \text { second-order rate constant }\left(\mathrm{M}^{-1} \mathrm{~s}^{-1}\right) \\ k_{1} & \text { second-order rate constant of the first abstracted H-atom }\left(\mathrm{M}^{-1} \mathrm{~s}^{-1}\right) \\ n_{\mathrm{t}} & \text { total stoichiometry }(\text { dimensionless) } \\ R_{0} & \text { initial reaction rate }\left(\mathrm{M}^{-1} \mathrm{~s}^{-1}\right) \\ t & \text { time (min) }\end{array}$

\section{Abbreviations}

$\begin{array}{ll}\text { AA } & \text { ascorbic acid } \\ \text { DES } & \text { deep eutectic solvent } \\ \text { DPPH } & \text { 2,2-diphenyl-1-picrylhydrazyl radical } \\ \text { HBA } & \text { hydrogen bond acceptor } \\ \text { HBD } & \text { hydrogen bond donor } \\ \text { m- } \beta \text {-CD } & \text { methyl } \beta \text {-cyclodextrin } \\ \text { OLL } & \text { olive leaves }\end{array}$

\section{References}

1. Moon, J.-K.; Shibamoto, T. Antioxidant assays for plant and food components. J. Agric. Food Chem. 2009, 57, 1655-1666. [CrossRef] [PubMed]

2. Obied, H.K.; Prenzler, P.D.; Omar, S.H.; Ismael, R.; Servili, M.; Esposto, S.; Taticchi, A.; Selvaggini, R.; Urbani, S. Pharmacology of olive biophenols. Adv. Mol. Toxicol. 2012, 6, 195-242.

3. López-Alarcón, C.; Denicola, A. Evaluating the antioxidant capacity of natural products: A review on chemical and cellular-based assays. Anal. Chim. Acta 2013, 763, 1-10. [CrossRef] [PubMed]

4. Goupy, P.; Dufour, C.; Loonis, M.; Dangles, O. Quantitative kinetic analysis of hydrogen transfer reactions from dietary polyphenols to the DPPH radical. J. Agric. Food Chem. 2003, 51, 615-622. [CrossRef] [PubMed]

5. Athanasiadis, V.; Grigorakis, S.; Lalas, S.; Makris, D.P. Methyl $\beta$-cyclodextrin as a booster for the extraction of Olea europaea leaf polyphenols with a bio-based deep eutectic solvent. Biomass Convers. Bioref. 2017. [CrossRef]

6. Athanasiadis, V.; Grigorakis, S.; Lalas, S.; Makris, D.P. Highly efficient extraction of antioxidant polyphenols from Olea europaea leaves using an eco-friendly glycerol/glycine deep eutectic solvent. Waste Biomass Valorization 2017. [CrossRef] 
7. Makris, D.P.; Passalidi, V.; Kallithraka, S.; Mourtzinos, I. Optimization of polyphenol extraction from red grape pomace using aqueous glycerol/tartaric acid mixtures and response surface methodology. Prep. Biochem. Biotechnol. 2016, 46, 176-182. [CrossRef] [PubMed]

8. Karvela, E.; Makris, D.P.; Karathanos, V.T. Implementation of response surface methodology to assess the antiradical behaviour in mixtures of ascorbic acid and $\alpha$-tocopherol with grape (Vitis vinifera) stem extracts. Food Chem. 2012, 132, 351-359. [CrossRef] [PubMed]

9. Shehata, E.; Grigorakis, S.; Loupassaki, S.; Makris, D.P. Extraction optimisation using water/glycerol for the efficient recovery of polyphenolic antioxidants from two Artemisia species. Sep. Purif. Technol. 2015, 149, 462-469. [CrossRef]

10. Brand-Williams, W.; Cuvelier, M.-E.; Berset, C. Use of a free radical method to evaluate antioxidant activity. LWT-Food Sci. Technol. 1995, 28, 25-30. [CrossRef]

11. Dangles, O.; Fargeix, G.; Dufour, C. One-electron oxidation of quercetin and quercetin derivatives in protic and non protic media. J. Chem. Soc. Perkin Trans. 2 1999, 1387-1396. [CrossRef]

12. Alluis, B.; Dangles, O. Quercetin (= 2-(3,4-dihydroxyphenyl)-3,5,7-trihydroxy-4H-1-benzopyran-4-one) glycosides and sulfates: Chemical synthesis, complexation, and antioxidant properties. Helv. Chim. Acta 2001, 84, 1133-1156. [CrossRef]

13. Villano, D.; Fernández-Pachón, M.; Moyá, M.; Troncoso, A.; García-Parrilla, M. Radical scavenging ability of polyphenolic compounds towards DPPH free radical. Talanta 2007, 71, 230-235. [CrossRef] [PubMed]

14. Mourtzinos, I.; Papadakis, S.E.; Igoumenidis, P.; Karathanos, V.T. Encapsulation of Melissa officinalis leaf's active compounds in $\beta$-cyclodextrin and modified starch. Procedia Food Sci. 2011, 1, 1679-1685. [CrossRef]

15. Diamanti, A.C.; Igoumenidis, P.E.; Mourtzinos, I.; Yannakopoulou, K.; Karathanos, V.T. Green extraction of polyphenols from whole pomegranate fruit using cyclodextrins. Food Chem. 2017, 214, 61-66. [CrossRef] [PubMed]

16. Medronho, B.; Valente, A.J.; Costa, P.; Romano, A. Inclusion complexes of rosmarinic acid and cyclodextrins: Stoichiometry, association constants, and antioxidant potential. Colloid Polym. Sci. 2014, 292, 885-894. [CrossRef]

17. Shao, P.; Zhang, J.; Fang, Z.; Sun, P. Complexing of chlorogenic acid with $\beta$-cyclodextrins: Inclusion effects, antioxidative properties and potential application in grape juice. Food Hydrocol. 2014, 41, 132-139. [CrossRef]

18. Lu, Z.; Cheng, B.; Hu, Y.; Zhang, Y.; Zou, G. Complexation of resveratrol with cyclodextrins: Solubility and antioxidant activity. Food Chem. 2009, 113, 17-20. [CrossRef]

19. Çelik, S.E.; Özyürek, M.; Güçlü, K.; Apak, R. Antioxidant capacity of quercetin and its glycosides in the presence of $\beta$-cyclodextrins: Influence of glycosylation on inclusion complexation. J. Inclus. Phenom. Macrocycl. Chem. 2015, 83, 309-319. [CrossRef]

20. Folch-Cano, C.; Jullian, C.; Speisky, H.; Olea-Azar, C. Antioxidant activity of inclusion complexes of tea catechins with $\beta$-cyclodextrins by ORAC assays. Food Res. Int. 2010, 43, 2039-2044. [CrossRef]

21. Mourtzinos, I.; Salta, F.; Yannakopoulou, K.; Chiou, A.; Karathanos, V.T. Encapsulation of olive leaf extract in $\beta$-cyclodextrin. J. Agric. Food Chem. 2007, 55, 8088-8094. [CrossRef] [PubMed]

22. Snelgrove, D.W.; Lusztyk, J.; Banks, J.; Mulder, P.; Ingold, K. Kinetic solvent effects on hydrogen-atom abstractions: Reliable, quantitative predictions via a single empirical equation. J. Am. Chem. Soc. 2001, 123, 469-477. [CrossRef]

23. García-Padial, M.; Martínez-Ohárriz, M.C.; Navarro-Blasco, I.; Zornoza, A. The role of cyclodextrins in ORAC-fluorescence assays. Antioxidant capacity of tyrosol and caffeic acid with hydroxypropyl- $\beta$-cyclodextrin. J. Agric. Food Chem. 2013, 61, 12260-12264. [CrossRef] [PubMed]

24. Álvarez-Parrilla, E.; Palos, R.; Rosa, L.A.; Frontana-Uribe, B.A.; González-Aguilar, G.A.; Machi, L.; Ayala-Zavala, J.F. Formation of two 1:1 chlorogenic acid: $\beta$-cyclodextrin complexes at pH 5: Spectroscopic, thermodynamic and voltammetric study. J. Mex. Chem. Soc. 2010, 54, 103-110.

25. Choueiri, L.; Chedea, V.S.; Calokerinos, A.; Kefalas, P. Antioxidant/pro-oxidant properties of model phenolic compounds. Part II: Studies on mixtures of polyphenols at different molar ratios by chemiluminescence and LC-MS. Food Chem. 2012, 133, 1039-1044. [CrossRef]

26. Karvela, E.; Makris, D.; Karathanos, V. Evaluation of mixture effects in binary solutions of ascorbic acid with grape (Vitis vinifera) seed extracts using response surface methodology. Int. Food Res. J. 2013, 20, 2193-2198.

27. Aoun, M.; Makris, D. Binary mixtures of natural polyphenolic antioxidants with ascorbic acid: Impact of interactions on the antiradical activity. Int. Food Res. J. 2012, 19, 603-606. 
28. Aoun, M.; Makris, D.P. Use of response surface methodology to evaluate the reducing power in binary solutions of ascorbic acid with natural polyphenolic antioxidants. Int. J. Food Stud. 2013, 2, 238-251. [CrossRef]

29. Sahin, S.; Samli, R.; Birteksöz Tan, A.S.; Barba, F.J.; Chemat, F.; Cravotto, G.; Lorenzo, J.M. Solvent-free microwave-assisted extraction of polyphenols from olive tree leaves: Antioxidant and antimicrobial properties. Molecules 2017, 22, 1056. [CrossRef] [PubMed]

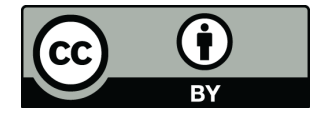

(C) 2017 by the authors. Licensee MDPI, Basel, Switzerland. This article is an open access article distributed under the terms and conditions of the Creative Commons Attribution (CC BY) license (http:/ / creativecommons.org/licenses/by/4.0/). 